\title{
CONTRIBUIÇÃO DE NUTRIENTES AO SOLO POR RESÍDUOS DE SERRARIA DE PINUS ${ }^{1}$
}

\author{
NUTRIENT CONTRIBUTION TO THE SOIL BY \\ PINUS RESIDUES FROM SAWMILL
}

\author{
Eleandro José Brun², Flávia Gizele Konig Brun³, \\ Mauro Valdir Schumacher ${ }^{4}$ e Gabriel Mancini Antunes da Silva ${ }^{5}$
}

\section{RESUMO}

Estimou-se a velocidade de decomposição e a liberação de nutrientes ao solo por resíduos de Pinus taeda L. proveniente de serraria, através da técnica de litter-bags, em duas áreas, um plantio recente e uma floresta de 4,5 anos de idade de Pinus taeda L. A cada estação, por dois anos, foram coletadas parte das bolsas acondicionadas junto ao solo, as quais foram avaliadas para estimar a decomposição e liberação de nutrientes. Ao final de dois anos, a liberação foi maior na área de plantio $(45,5 \%)$ em relação à área de floresta $(37,1 \%)$, de forma linear durante o estudo. Os teores de nutrientes variaram de acordo com suas características elementares e condições microclimáticas específicas, diminuindo, aumentando ou mantendo teores estáveis no resíduo remanescente. A decomposição destes resíduos pode ser entendida como uma fonte de nutrientes de lenta liberação, os quais podem ser absorvidos de forma mais eficiente pelas raízes, além de realizarem a proteção física do solo. Estima-se, com a aplicação de $25 \mathrm{Mg} \mathrm{ha}^{-1}$ de resíduo, um incremento de nutrientes, através da análise química dos nutrientes presentes no resíduo, que houve um aumento para $\left(\mathrm{kg} \mathrm{ha}^{-1}\right)$ : 85,0 $(\mathrm{N}) ; 1,75(\mathrm{P}) ; 116,3(\mathrm{~K})$, 37,0 (Ca); 9,0 (Mg); 16,0 (S); $9650(\mathrm{C}) ; 67,3$ (Fe); 0,42 (B); 0,60 (Zn); 0,18 (Cu) e 3,98 (Mn), compensando parte das saídas de nutrientes em função de desbastes e colheita.

Palavras-chave: resíduos orgânicos, ciclagem de nutrientes, sustentabilidade florestal.

\section{ABSTRACT}

The decomposition speed and the release of nutrients to the soil by Pinus taeda L. residues from the sawmill were estimated through the litter-bag technique in two areas, a recent planting and a 4.5-year-old forest of Pinus taeda L. At each season, for two years, part of the bags stored on the ground were collected, which were evaluated to estimate the decomposition and release of nutrients. At the end of two years, the release was greater in the planting area (45.5\%) compared to the forest area (37.1\%), linearly during the study. Nutrient contents varied according to their elementary characteristics and specific microclimate conditions, decreasing, increasing or maintaining stable levels in the remaining residue. The decomposition of these residues can be a

1 Trabalho realizado em cooperação técnico-científica entre pesquisadores da Universidade Federal de Santa Maria (UFSM) e Universidade Tecnológica Federal do Paraná Campus Dois Vizinhos (UTFPR-DV), em parceria com empresas do setor florestal.

2 Eleandro José Brun - Engenheiro Florestal, Dr. Professor dos cursos de Engenharia Florestal, Agronomia e do Programa de Pós-graduação em Agroecossistemas da UTFPR Campus Dois Vizinhos. E-mail: eleandrobrun.utfpr@gmail.com

3 Flávia Gizele König Brun - Engenheira Florestal, Dra. Professora dos cursos de Engenharia Florestal e Agronomia da UTFPR Campus Dois Vizinhos. E-mail: flaviag@utfpr.edu.br

4 Mauro Valdir Schumacher - Engenheiro Florestal, Dr. Professor do Departamento de Ciências Florestais da UTFPR. E-mail: mvschumacher@gmail.com

5 Gabriel Mancini Antunes da Silva - Engenheiro Florestal, Mestrando em Engenharia Florestal na UDESC - Centro de Ciências Agroveterinárias. E-mail: twilight.mancini@hotmail.com. 
source of slow-release nutrients, which can be absorbed more efficiently by the roots, in addition to providing physical protection for the soil. It is estimated, with the application of $25 \mathrm{Mg} \mathrm{ha}^{-1}$ of residue, an increase in nutrients through chemical analysis of residue's nutrientes with a increase for $\left(\mathrm{kg} \mathrm{ha}^{-1}\right): 85.0(\mathrm{~N}) ; 1.75(P)$; $116.3(\mathrm{~K})$, $37.0(\mathrm{Ca}) ; 9.0(\mathrm{Mg}) ; 16.0(\mathrm{~S}) ; 9650(\mathrm{C}) ; 67.3$ (Fe); $0.42(\mathrm{~B}) ; 0.60(\mathrm{Zn}) ; 0.18(\mathrm{Cu})$ and $3.98(\mathrm{Mn})$, offsetting part of the nutrient output due to thinning and harvesting.

Key words: organic residues, nutrients cycling, forest sustainability.

\section{INTRODUÇÃO}

As árvores exercem importante papel sobre os sistemas em que estão inseridas, pois ao longo do crescimento e desenvolvimento, a vegetação arbórea adiciona matéria orgânica ao solo via deposição de serapilheira e renovação do sistema radicular, exercendo influência sobre os atributos físicos do solo, como a densidade, porosidade, aeração, capacidade de infiltração e retenção de água, bem como a formação e estabilização dos agregados (CUNHA NETO et al., 2013).

Em muitas empresas que processam madeira como matéria-prima, os resíduos dos processos produtivos, principalmente de serrarias, por serem materiais sólidos, que não sofreram severos tratamentos químicos capazes de causar impacto ambiental negativo no ecossistema, têm a possibilidade de serem aproveitados com sucesso na devolução de parte dos nutrientes retirados do povoamento por ocasião da colheita (FRUMHOLF, 1995).

Esses resíduos terão seu processo de decomposição e liberação de nutrientes ao solo influenciado por fatores como o componente arbóreo, o qual, por sua vez, influencia na fertilidade do solo, além de promover um microclima que favorece o desenvolvimento de diversos organismos, sendo a serapilheira acumulada resultado de um equilíbrio entre as taxas de deposição e de decomposição dos resíduos (SCHUMACHER et al., 2011; CUNHA NETO et al., 2013).

Além disso, em povoamentos que sofreram corte raso ou desbaste, a devolução de resíduos de colheita ao solo formará uma camada protetora contra efeitos nocivos da erosão hídrica e da insolação excessiva, como perdas de solo e nutrientes, poluição de rios, lagos e lagoas, perdas econômicas por investimentos em recuperação da fertilidade do solo, entre outros (BRUN et al., 2010).

A absorção dos nutrientes liberados pela decomposição do material orgânico depositado sobre o solo, irá depender da exigência da espécie, da taxa de crescimento e das condições edafoclimáticas, as quais influenciam na disponibilidade desses nutrientes para as plantas (LUZ et al., 2002). Vale lembrar que a taxa de absorção é maior nas idades mais jovens do povoamento, culminando com a maior taxa de produtividade. Assim, para um bom manejo do excesso de resíduos orgânicos em decomposição, faz-se amplamente necessário conhecer o tempo médio da decomposição do mesmo, para planejar a distribuição do mesmo e a variação desses nutrientes em relação a quantidade de matéria orgânica no solo. 
Entre os métodos mais usados para estimar a perda de massa orgânica de serapilheira e resíduos vegetais está a coleta destes e o acondicionamento em sacos feitos de malha de nylon, a qual pode ter malha de tamanho variável, dependendo do objetivo do estudo e desde que permita a entrada de diferentes tipos de organismos que atuarão na decomposição dos resíduos (BRUN et al., 2010; VALENTINI et al., 2014).

Com base nos aspectos acima levantados, este estudo teve por objetivo estimar a velocidade de decomposição dos resíduos de madeira de Pinus taeda L. proveniente de serraria, sendo o mesmo utilizado como adubação orgânica; a fim de determinar a liberação de nutrientes do material sob decomposição nas bolsas (litter-bags), bem como quantificar as perdas que o mesmo sofre para o solo (a cada estação do ano), oferecendo indicações silviculturais a respeito do aporte de nutrientes ao solo, via decomposição de resíduos de madeira dispostos sobre o mesmo.

\section{MATERIAL E MÉTODOS}

O estudo foi desenvolvido em área de empresa florestal no município de Cambará do Sul-RS, localizada na latitude $29^{\circ} 02^{\prime} 15^{\prime}$ 'Sul e longitude $50^{\circ} 09^{\prime} 20^{\prime \prime}$ Oeste, em empresa que trabalha no ramo de serraria, com a produção de madeira sólida beneficiada para diversos fins (CIDADE-BRASIL, 2020).

O tipo de clima fundamental predominante na região é o $\mathrm{Cfb}$ (temperado úmido) com precipitação média anual de $1881 \mathrm{~mm}$, bem distribuída durante o ano. A temperatura média anual é de aproximadamente $14,9^{\circ} \mathrm{C}$, sendo que a média das máximas é de $19,7^{\circ} \mathrm{C}$ e a média das mínimas é de $10,1^{\circ} \mathrm{C}$. Nesta região ocorrem cerca de 40 geadas por ano, principalmente no período de abril a novembro, e queda de neve em cerca de três dias por ano. Os ventos dominantes na região são os alísios, ou seja, sopram do mar para a terra, devido à região situar-se próximo ao litoral norte do estado do RS (ALVARES et al., 2013; CLIMATE DATA, 2020).

O solo da região classifica-se como Cambissolo Húmico alumínico típico, profundo, moderadamente drenado, com cores bruno-avermelhadas, argiloso, friável e desenvolvido a partir de rochas eruptivas básicas (basalto). Os solos são fortemente ácidos, com saturação e soma de bases baixas e teores altos de alumínio trocável e matéria orgânica (STRECK et al., 2018).

No geral, o solo apresenta fertilidade baixa a muito baixa, fazendo com que grande parte dos nutrientes dos povoamentos de pinus plantados nestes solos estejam imobilizados na biomassa das árvores. Dentre as características químicas do solo, as que apresentam maior relação com o crescimento radicular estão a acidez e a deficiência de nutrientes (LOPES et al., 2010).

O estudo foi realizado por dois anos em duas áreas previamente selecionadas de cultivo de Pinus taeda L. Na ocasião da implantação do experimento, a Área A se tratava de um corte raso onde havia ocorrido o plantio de nova rotação no mesmo mês da implantação do estudo e; a Área B era um plantio com 4,5 anos de idade (Figura 1). 
Figura 1 - Fotos ilustrativas das áreas de estudo a campo. A: área de corte raso e plantio recente; B: área de plantio com 4,5 anos de idade. Em ambas as áreas estava ocorrendo a demarcação das parcelas amostrais, no momento da foto.

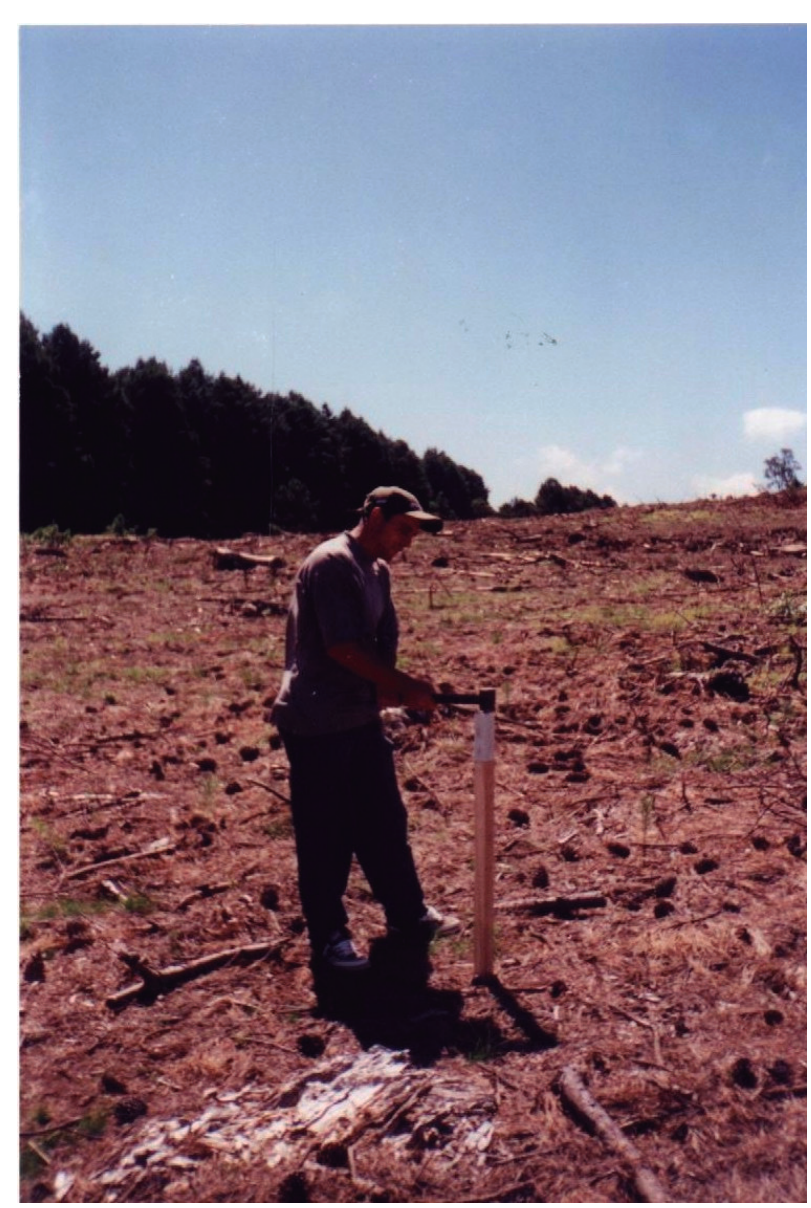

A

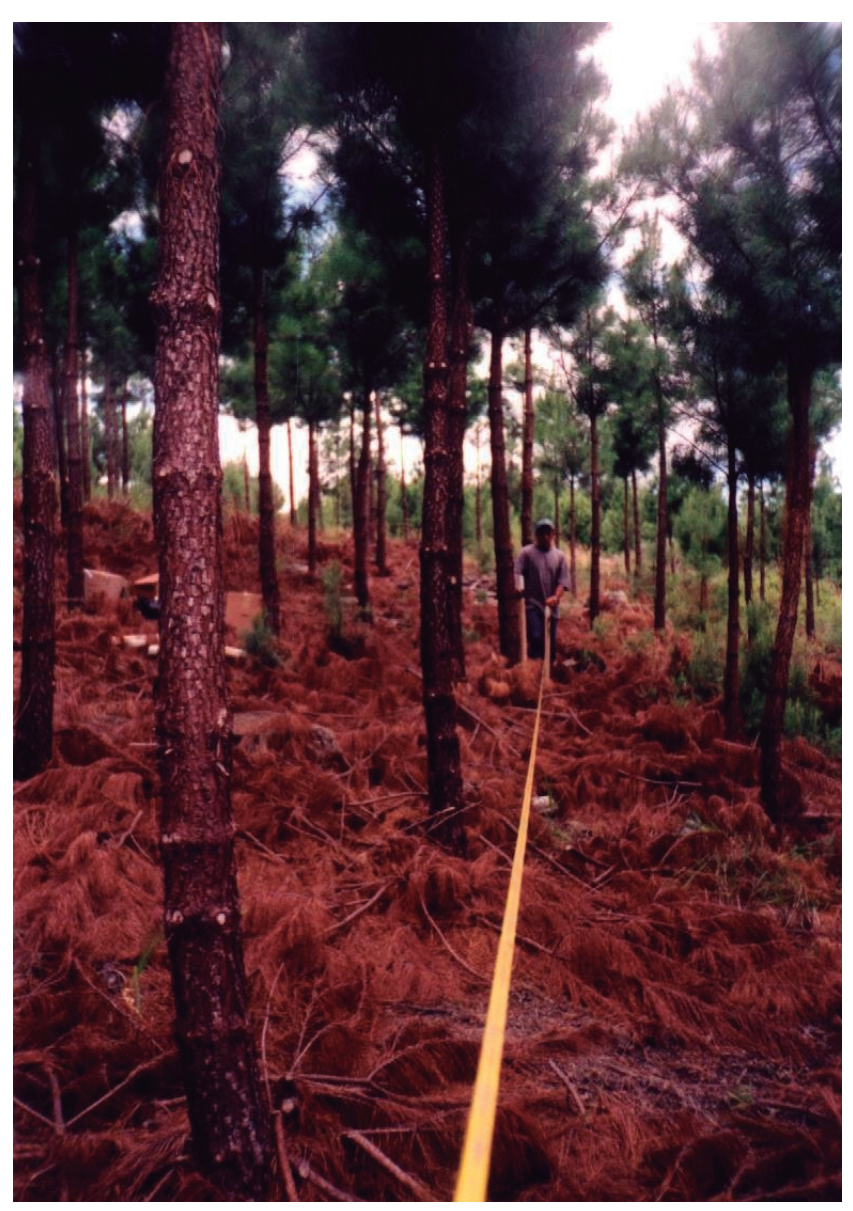

B

Conforme a Figura 1, a Área A caracteriza-se pela incidência dos raios solares diretamente no solo, serapilheira ou vegetação rasteira, influenciando assim muitos fatores envolvidos na decomposição da matéria orgânica, como alta variação no teor de umidade superficial, temperatura da superfície e subsuperfície do solo e atividade microbiana. Enquanto, na área B, considerando as características da espécie, o espaçamento e o manejo utilizado na empresa, o dossel da floresta estava, na maior parte, fechado a partir desta idade, propiciando condições diferenciadas de decomposição de matéria orgânica, geralmente contrárias à situação da Área A, com sombreamento elevado, formação de camada de serapilheira e biomassa da primeira desrama realizada aos 4 anos ainda boa parte em decomposição sobre o solo.

Primeiramente, os resíduos provenientes do depósito a céu aberto da serraria foram coletados em sacos e postos a secar em estufa de circulação e renovação de ar a $65^{\circ} \mathrm{C}$ por um período de 72 horas. Em virtude da grande quantidade de resíduos presentes no pátio da empresa (em torno de 200.000 Mg) e dos diferentes graus de decomposição, variável em função do aumento da profundidade do monte de resíduos, foi utilizada uma retroescavadeira para a abertura de um buraco no monte, 
até o alcance máximo da máquina (aproximadamente $5 \mathrm{~m}$ de profundidade). $\mathrm{O}$ resíduo das diferentes camadas foi misturado de forma homogênea para a coleta.

Estes resíduos, devido a sua origem da serraria, eram formados, predominantemente, por serragem de pequenas dimensões (entre $1 \mathrm{~mm}$ até $5 \mathrm{~mm}$ de diâmetro superficial), os quais, após a secagem, os resíduos foram acondicionados em sacos de papel para envio à floresta. $\mathrm{O}$ acondicionamento, em bolsas de nylon (malha de $3 \mathrm{~mm}$ ), foi feito a campo. As bolsas de $n y l o n$ tinham dimensões de 20 x $20 \mathrm{~cm}$, com capacidade de 100 gramas de resíduo seco em cada uma, equivalente a uma quantidade de $25 \mathrm{Mg} \mathrm{ha}^{-1}$ de resíduo a ser aplicado sobre o solo, no experimento.

Para a instalação do experimento, unidades amostrais foram demarcadas nas duas áreas, com distribuição na forma de blocos aleatórios, com quatro blocos para cada área, cada um contendo os oito tratamentos, relativos ao tempo de permanência das bolsas nas áreas de pesquisa $\mathrm{A}$ e $\mathrm{B}$, os quais tiveram coletas estacionais (a cada três meses), durante dois anos de estudo, na quantidade de 6 litter-bags por tratamento, como repetição.

$\mathrm{Na}$ ocasião da coleta das amostras instaladas a campo, cada litter-bag era, depois de localizado, retirado com cuidado da superfície do solo e devidamente embalado em embalagem plástica, a qual era identificada com a área a que pertencia, o bloco, tratamento e o número da amostra.

As amostras, após serem trazidas ao laboratório, foram primeiramente abertas para catação de material adverso, como raízes de ervas invasoras, de grande incidência, insetos ou outro material que não tivesse origem no resíduo que havia sido colocado na implantação da pesquisa. Após isso, as amostras foram secas em estufa de renovação e circulação de ar a $65^{\circ} \mathrm{C}$ por 72 horas e, em seguida, pesadas em balança digital $(0,01 \mathrm{~g})$.

Para a análise química do material, as seis amostras de cada tratamento, em cada bloco, foram reunidas e homogeneizadas em uma amostra composta, visando à moagem em moinho tipo wiley (marca Marconi, MA680) com peneira de 30 mesh, e posterior análise química.

A análise química, quanto aos teores de N, P, K, Ca, Mg, S, B, Cu, Fe, Mn, Zn e C orgânico foi realizada com base na metodologia descrita em Tedesco et al. (1995). As amostras foram, inicialmente, digeridas através de solução digestora $\left(\mathrm{Na}_{2} \mathrm{SO}_{4}, \mathrm{CuSO}_{4} 5 \mathrm{H}_{2} \mathrm{O}, \mathrm{H}_{2} \mathrm{SO}_{4}\right.$ e água destilada) em tubos de digestão acondicionados em bloco digestor, em sistema de digestão úmida aberta. Posteriormente, os extratos gerados na digestão foram diluídos e cada elemento foi determinado por método específico: N por titulação (Método Kjeldahl); P (660 nm) e B (460 nm) por espectrofotômetro UV-VIS; K por fotometria de chama; $\mathrm{Ca}, \mathrm{Mg}$, $\mathrm{Fe}, \mathrm{Cu}, \mathrm{Mn}$ e $\mathrm{Zn}$ foram determinados por espectrofotometria de absorção atômica; Carbono orgânico (C) foi determinado por oxirredução via úmida (método de Walkley-Black); $\mathrm{S}$ foi determinado por turbidimetria e realizadas as leituras em espectrofotômetro UV-VIS (420 nm). Uma descrição completa dos métodos pode ser encontrada em Ferreira (2014). 
Os dados de perda de peso das amostras nos dois anos de estudo, bem como as variações nos teores de nutrientes nas amostras foram submetidos à análise de variância e teste de comparação de médias com o uso do software SSPS v. 22.0 for Windows.

\section{RESULTADOS E DISCUSSÃO}

Ao final de dois anos de avaliação, a perda de resíduo por decomposição chegou a 45,46\% na área de plantio recente (floresta de 2 anos na época da última coleta de dados), sendo estatisticamente superior aos 37,14\% perdidos na floresta com 4,5 anos (6,5 anos ao término do experimento) (Tabela 1). Ao final do primeiro ano de estudo, as perdas ainda eram maiores na floresta (com 4,5 anos), porém, no decorrer do segundo ano de estudo, as perdas de resíduos para o solo se acentuaram em favor da área de plantio, sendo a decomposição e liberação de resíduos para o solo superior à floresta ao final do período avaliado.

Tabela 1 - Perda estacional de resíduos de serraria ( $\mathrm{g}$ e \%) acondicionados em litter-bags distribuídos sobre o solo do planto e na floresta.

\begin{tabular}{ccccc}
\hline \multirow{2}{*}{ Coleta das bolsas } & \multicolumn{2}{c}{ Peso médio das bolsas $(\mathrm{g})$} & \multicolumn{2}{c}{ Perda média de peso (\%) } \\
\cline { 2 - 5 } & Plantio & Floresta 4,5 anos & Plantio & Floresta 4,5 anos \\
\hline Peso inicial & $100,00 \mathrm{~A}^{\mathrm{a}} \mathrm{a}^{2}$ & $100,00 \mathrm{~A} \mathrm{a}$ & 0 & 0 \\
\hline Verão/Ano 1 & $90,25 \mathrm{~A} \mathrm{~b}$ & $90,26 \mathrm{~A} \mathrm{~b}$ & 9,75 & 9,74 \\
\hline Outono/Ano 1 & $83,38 \mathrm{~A} \mathrm{c}$ & $81,49 \mathrm{~A} \mathrm{c}$ & 16,62 & 18,51 \\
\hline Inverno/ Ano 1 & $81,55 \mathrm{~A} \mathrm{c}$ & $80,20 \mathrm{~A} \mathrm{c}$ & 18,45 & 19,80 \\
\hline Primavera/ Ano 1 & $78,01 \mathrm{~A} \mathrm{c}$ & $74,61 \mathrm{~B} \mathrm{~d}$ & 22,00 & 25,39 \\
\hline Verão/ Ano 2 & $64,68 \mathrm{~B} \mathrm{~d}$ & $71,33 \mathrm{~A} \mathrm{~d}$ & 35,32 & 28,67 \\
\hline Outono/ Ano 2 & $61,38 \mathrm{~B} \mathrm{de}$ & $70,66 \mathrm{~A} \mathrm{~d}$ & 38,62 & 29,34 \\
\hline Inverno/ Ano 2 & $56,78 \mathrm{~B} \mathrm{ef}$ & $64,57 \mathrm{~A} \mathrm{e}$ & 43,22 & 35,43 \\
\hline Primavera/ Ano 2 & $54,54 \mathrm{~B} \mathrm{f}$ & $62,86 \mathrm{~A} \mathrm{e}$ & 45,46 & 37,14 \\
\hline
\end{tabular}

1. Médias seguidas pela mesma letra maiúscula, na linha, não diferem entre si pelo Teste $\mathrm{F}$ (ANOVA), a 1\% de probabilidade de erro; 2. Médias seguidas pela mesma letra minúscula, na coluna, não diferem entre si pelo Teste de Tukey, a 1\% de probabilidade de erro.

Fonte: Elaborada pelos autores, 2020.

A decomposição de resíduos orgânicos pode ser dividida em três processos básicos: lixiviação ou lavagem (a), intemperismo ou ruptura física do material (b) e ação biológica (c), com a oxidação do material. Inicialmente predomina a lixiviação, mas com o tempo todos passam a atuar simultaneamente (SIGNOR e DIONISIO, 2016). A avaliação da decomposição de resíduos orgânicos por meio da técnica de litter-bags contempla, de forma mais eficiente, as duas primeiras etapas, uma vez que a atividade biológica sobre o resíduo instalado vai se dar quando o mesmo já esteja incorporado ao solo, após a perda devido a sua fragmentação. Porém, em virtude da riqueza nutricional do mesmo, a ação de organismos fragmentadores pode iniciar-se já quando da exposição deste material no ecossistema. 
Além disso, a quantidade de nutrientes disponibilizados pela decomposição da serapilheira demonstra a importância dessa ciclagem biogeoquímica para o suprimento de nutrientes no sítio florestal e ainda que o acúmulo de biomassa de pinus ocorre prioritariamente na madeira comercial, seguida pelos galhos vivos, casca comercial, acículas, madeira do ponteiro, galhos mortos e casca do ponteiro, nesse contexto, a casca e os demais resíduos (acículas, galhos e ponteiros) correspondem a pelo menos 50\% da quantidade de nutrientes extraídos do solo pelas plantas (VIERA et al., 2011; VIERA et al., 2013).

Acredita-se que os resultados apresentados sejam explicados pelo fato de que, no plantio, quando da implantação do experimento, por este ser recente, a pouca quantidade de raízes, a insolação direta nas amostras, com menor umidade do resíduo, pode ter inibido a ação de agentes decompositores de matéria orgânica, tanto macro como micro decompositores, fazendo com que a liberação de resíduos para o solo fosse menor no primeiro ano.

Para o segundo ano, com o crescimento das plantas de Pinus taeda e, principalmente da vegetação concorrente (como gramíneas, regeneração do próprio pinus e espécies típicas das florestas naturais da região) proporcionou um aumento em quantidade de raízes atuando sobre as amostras, as quais abriram caminho para pequenos e grandes decompositores. Estes, auxiliados pela proteção da vegetação, quanto aos raios solares diretos (maior umidade nas amostras), atacaram o material das bolsas, propiciando a maior perda de peso destes resíduos no segundo ano, na área de plantio (BRUN et al., 2010).

Estas situações descritas, que se acentuaram no segundo ano no plantio, já ocorriam, de certa forma, na floresta, porém não em igualdade de condições, uma vez que a mesma, devido à maior idade, apresenta uma baixa abundância de vegetação concorrente, sendo menor o ataque de raízes nas amostras, as quais são provenientes, na maioria, das árvores de pinus da referida floresta, encobertas pela camada de serapilheira que já se forma nesta área.

Observando-se os dados, vê-se que no período do inverno, principalmente no primeiro ano, praticamente não houve perda de material, uma vez que a baixa temperatura funciona como um agente inibidor da atividade dos organismos vivos. No inverno do segundo ano de estudo, isto não é verificado, uma vez que o material das amostras, já em maior grau de decomposição, é mais facilmente liberado das bolsas, demonstrando que a influência do tempo de exposição do material em campo influencia no seu grau de degradabilidade. Além disso, em materiais em estágio mais avançado de decomposição, os agentes biológicos decompositores são outros (colêmbolos, fungos e bactérias) em relação aos que atuam em estágio inicial de degradação (insetos em geral).

Entre os fatores que influem na velocidade de decomposição do material vegetal depositado no solo de uma floresta estão o tipo de vegetação, altitude, latitude, precipitação, temperatura, regimes de luminosidade, relevo, deciduosidade, estágio sucessional, disponibilidade hídrica e características do solo (NUNES et al., 2012). Estes autores relataram, em seu estudo, que o tempo de exposição do material vegetal e a ação da fauna de solo foram preponderantes para a velocidade de decomposição da serapilheira. 
Sob o aspecto da temperatura, Bauer et al. (2018) observaram uma menor perda de peso de serapilheira nos meses de temperatura mais baixa, fato coincidente com os resultados do presente estudo para o primeiro inverno, mas no segundo, tendo em vista o estágio mais avançado de degradação do material, mesmo no inverno houve perda de peso.

Quanto à precipitação, Santana e Souto (2011) e Dick et al. (2015) constataram uma maior velocidade de decomposição nas estações mais chuvosas. Este fato é pouco pronunciado neste estudo, tendo em vista que, apesar da reconhecida influência da umidade na decomposição, a não ocorrência de períodos secos e nem chuvas torrenciais no período de estudo fizeram com que o fator tivesse menor influência em relação aos demais.

Sutili e Schumacher (2002) estudaram a perda de peso de folhas ocorrida estacionalmente, com o uso de litter bags semelhantes às do presente estudo, porém em uma Floresta Estacional Decidual de Santa Maria/RS, onde relataram que no período inicial, de inverno, a perda de massa se deu de uma forma mais lenta, ocorrendo de forma mais acelerada no período de primavera e verão, sendo que após um ano de exposição na floresta a biomassa foi reduzida a 48\% do original. As causas dessa decomposição acelerada nas estações mais quentes (primavera e verão), estão relacionadas ao aumento de temperatura, aumento da umidade e oxigenação do solo, que irão promover um ambiente mais propício a proliferação de organismos decompositores, em detrimento do inverno (HOLANDA et al., 2015).

No estudo de Giácomo et al. (2012), para uma área de floresta mesofítica (área mais fechada pelo dossel das árvores) e para o Cerradão (área mais aberta, por não ter um dossel tão fechado), pode-se verificar que o processo de decomposição do material foliar nos primeiros 30 e 60 dias após a instalação dos "litter bags" ocorreu com maior intensidade na área de mata mesofítica, apresentando perda de massa de $17,9 \%$ e $37,5 \%$, enquanto para a área de cerradão a perda foi de $16 \%$ e $19,7 \%$. Aos 120 dias, este padrão se inverteu e as maiores perdas de massa foram verificadas na área de cerradão (41,4\%) e na área de mata (37,5\%). Entretanto, aos 210 dias a área de mata mesofítica voltou a apresentar o maior valor de decomposição, aproximadamente $60,4 \%$ de sua massa decomposta contra 55,5\% na área de cerradão.

Os valores de decomposição encontrados no presente estudo representam um significativo aporte de nutrientes ao solo, com base no valor inicial, porém ainda não são valores ideais para que a decomposição se processe em velocidade semelhante a serapilheira de uma floresta natural, por exemplo. Nestas condições, o resíduo estudado apresenta uma baixa atratividade (alta relação C/N - Figura 2) para a fauna decompositora, que tende a usar materiais como estes somente em casos de maior necessidade. Com o avanço do estágio de decomposição do material, a relação tende a diminuir, tornando o material mais atrativo.

Sendo assim, a relação $\mathrm{C} / \mathrm{N}$ do resíduo aumentou em relação ao valor inicial, nos meses de março (verão), chegando a um pico em junho (outono), devido principalmente às diminuições ocorridas na concentração de N (Tabela 2). Após esse período, o valor diminuiu gradativamente a partir de 
setembro, chegando a valores próximos ao inicial em dezembro (primavera). Durante o segundo ano de estudo, a relação $\mathrm{C} / \mathrm{N}$ do resíduo apresentou diminuições gradativas, chegando a valores de 85 e 95 , na área de plantio e na floresta de 4,5 anos, respectivamente.

Figura 2 - Variação da relação $\mathrm{C} / \mathrm{N}$ no resíduo de serraria coletado periodicamente no plantio e na floresta de 4,5 anos de Pinus taeda

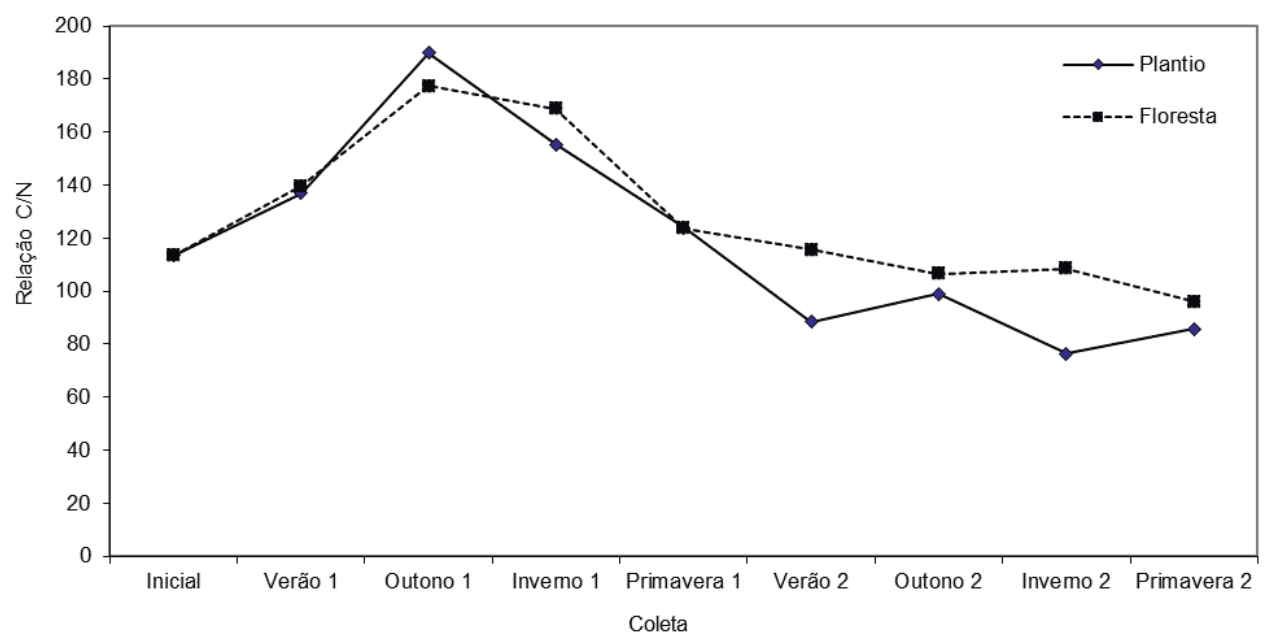

Fonte: Elaborada pelos autores, 2020.

Principalmente em solos de baixa fertilidade, é comum serem observadas as raízes das plantas crescendo de forma intensa na interface solo-serapilheira, esta proveniente tanto da queda natural de material das árvores ou como subproduto de intervenções silviculturais na floresta. Reissmann e Wisniewski (2005) concluíram que a maior eficiência na absorção de nutrientes que vão sendo liberados gradativamente varia de acordo com o grau de decomposição do resíduo sobre o solo.

Mesmo que a taxa de liberação dos resíduos de Pinus taeda para o solo (decomposição) nas duas áreas estudadas seja inferior aos dados oriundos de pesquisas em florestas naturais, pode-se fazer algumas inferências silviculturais que remetem a vantagens do uso dos resíduos na cobertura do solo. Considerando que, no caso específico do empreendimento estudado, o depósito de resíduos acumulado era de cerca de $200.000 \mathrm{Mg}$, uma taxa de liberação de $1 \%$ significa que a cada estação são devolvidos ao solo cerca de $2.000 \mathrm{Mg}$ de resíduos, podendo ser aplicados em cerca de 80 ha de plantio anual.

Tal hipótese considera que o tamanho da amostra levada a campo (litter-bag), era de 0,2 x $0,2 \mathrm{~m}$, contendo uma quantidade de $100 \mathrm{~g}$ de resíduo, isso equivaleria a espalhar sobre o solo $25 \mathrm{Mg}$ ha $^{-1}$ de resíduo, e que restaria, ao final de 2 anos, somente, na média das duas áreas pesquisadas, 14,7 $\mathrm{Mg} \mathrm{ha}^{-1}$. Se, por um lado, este material restante ainda não decompôs e, consequentemente, ainda não liberou seus nutrientes para o solo, por outro, fica sobre a superfície do mesmo, tendo uma importante função de ser uma proteção física contra os efeitos danosos da erosão hídrica, sendo uma fonte de nutrientes de lenta liberação.

Quanto à caracterização nutricional do resíduo avaliado a cada estação do ano (Tabela 2), o teor inicial de macronutrientes no resíduo recolhido a campo foi comparado aos dados obtidos nas 
amostras coletadas nas estações subsequentes, aos 3, 6, 9, 12, 15, 18, 21 e 24 meses após a implantação do experimento.

Tabela 2 - Teores de macronutrientes no resíduo depositado sobre o solo e recolhido após $3,6,9,12,15,18,21$ e 24 meses de campo, em plantio e floresta de 4,5 anos de Pinus taeda.

\begin{tabular}{|c|c|c|c|c|c|c|c|c|}
\hline \multirow{2}{*}{$\begin{array}{c}\text { Data de } \\
\text { Coleta }\end{array}$} & \multirow{2}{*}{ Local } & $\mathbf{N}$ & $\mathbf{P}$ & $\mathbf{K}$ & $\mathrm{Ca}$ & Mg & $\mathbf{S}$ & C org. \\
\hline & & \multicolumn{7}{|c|}{$\mathrm{g} \mathrm{kg}^{-1}$} \\
\hline \multirow{2}{*}{ Teor inicial } & Plantio & $3,40 \mathrm{c} * \mathrm{~ns}$ & $0,07 \mathrm{c}^{\mathrm{ns}}$ & $4,65 \mathrm{a}^{\mathrm{ns}}$ & $1,48 a^{n s}$ & $0,36 b^{\text {ns }}$ & $0,64 \mathrm{c}^{\mathrm{ns}}$ & $386 b^{n s}$ \\
\hline & Floresta & $3,30 \mathrm{~b}$ & $0,08 \mathrm{~d}$ & $4,72 \mathrm{a}$ & $1,55 \mathrm{a}$ & $0,41^{\mathrm{ns}}$ & $0,74 \mathrm{c}$ & $397 \mathrm{~b}$ \\
\hline Verão / & Plantio & $2,90 \mathrm{c} \mathrm{A}$ & 0,13 c A & $4,02 b^{\mathrm{ns}}$ & $1,13 \mathrm{~b} \mathrm{~A}$ & $0,46 b^{\mathrm{ns}}$ & 0,20 e $\mathrm{B}$ & $397 \mathrm{~b} \mathrm{~A}$ \\
\hline Ano 1 & Floresta & $2,51 \mathrm{c} \mathrm{B}$ & $0,09 \mathrm{~d} \mathrm{~B}$ & $4,21 \mathrm{~b}$ & $0,91 \mathrm{c} \mathrm{B}$ & 0,36 & $0,36 \mathrm{~d} \mathrm{~A}$ & $350 \mathrm{c} \mathrm{B}$ \\
\hline Outono / & Plantio & $2,11 \mathrm{~d}^{\mathrm{ns}}$ & 0,19 b B & $3,14 \mathrm{c}^{\mathrm{ns}}$ & $1,32 b^{\mathrm{ns}}$ & $0,30 b^{\mathrm{ns}}$ & $1,11 b^{n s}$ & $400 b^{\text {ns }}$ \\
\hline Ano 1 & Floresta & $2,19 \mathrm{c}$ & 0,72 a $A$ & $3,37 \mathrm{c}$ & $1,29 \mathrm{~b}$ & 0,33 & $1,14 \mathrm{~b}$ & $389 \mathrm{~b}$ \\
\hline Inverno / & Plantio & $2,58 \mathrm{~d}^{\mathrm{ns}}$ & 0,39 a $\mathrm{B}$ & $3,18 \mathrm{c}^{\mathrm{ns}}$ & $1,57 a^{\mathrm{ns}}$ & $0,35 \mathrm{~b}^{\mathrm{ns}}$ & $1,15 b^{\mathrm{ns}}$ & $400 b^{n s}$ \\
\hline Ano 1 & Floresta & $2,41 \mathrm{c}$ & 0,76 a $\mathrm{A}$ & $3,14 \mathrm{c}$ & $1,47 \mathrm{a}$ & 0,34 & $1,05 \mathrm{~b}$ & $407 \mathrm{~b}$ \\
\hline Primavera / & Plantio & $3,27 \mathrm{c}^{\mathrm{ns}}$ & $0,24 b^{n s}$ & $3,20 \mathrm{c}^{\mathrm{ns}}$ & $1,18 b^{\mathrm{ns}}$ & $0,33 b^{\mathrm{ns}}$ & $1,22 \mathrm{a}^{\mathrm{ns}}$ & $405 b^{\text {ns }}$ \\
\hline Ano 1 & Floresta & $3,23 \mathrm{~b}$ & $0,21 \mathrm{c}$ & $3,17 \mathrm{c}$ & $1,06 \mathrm{c}$ & 0,30 & $1,26 \mathrm{a}$ & $399 \mathrm{~b}$ \\
\hline Verão / & Plantio & $4,78 \mathrm{~b} \mathrm{~A}$ & $0,32 a^{n s}$ & $0,62 \mathrm{~d} A$ & 1,53 a $A$ & 0,69 a $A$ & $0,49 \mathrm{~d}^{\mathrm{ns}}$ & 422 a B \\
\hline Ano 2 & Floresta & 3,89 a B & $0,23 \mathrm{c}$ & $0,28 \mathrm{~d} \mathrm{~B}$ & $1,15 \mathrm{c} \mathrm{B}$ & $0,30 \mathrm{~B}$ & $0,38 \mathrm{~d}$ & 450 a $\mathrm{A}$ \\
\hline Outono / & Plantio & $4,37 b^{n s}$ & $0,33 a^{n s}$ & $0,59 \mathrm{~d} A$ & 1,38 a $A$ & 0,72 a $A$ & $0,44 \mathrm{~d}^{\mathrm{ns}}$ & $433 a^{\text {ns }}$ \\
\hline Ano 2 & Floresta & $4,13 \mathrm{a}$ & $0,25 \mathrm{c}$ & $0,33 \mathrm{~d} \mathrm{~B}$ & $1,00 \mathrm{c} \mathrm{B}$ & $0,29 \mathrm{~B}$ & $0,39 \mathrm{~d}$ & $441 \mathrm{a}$ \\
\hline Inverno / & Plantio & 5,46 a $\mathrm{A}$ & $0,34 a^{\text {ns }}$ & $0,60 \mathrm{~d} A$ & 1,48 a $\mathrm{A}$ & 0,70 a $\mathrm{A}$ & $0,53 \mathrm{~d}^{\mathrm{ns}}$ & $417 a^{\text {ns }}$ \\
\hline Ano 2 & Floresta & 4,03 a B & $0,29 \mathrm{~b}$ & $0,42 \mathrm{~d} \mathrm{~B}$ & 0,98 с B & $0,36 \mathrm{~B}$ & $0,43 \mathrm{~d}$ & $438 \mathrm{a}$ \\
\hline Primavera / & Plantio & $5,07 \mathrm{a}^{\mathrm{ns}}$ & $0,34 \mathrm{a}^{\mathrm{ns}}$ & $0,54 \mathrm{~d} A$ & $1,20 b^{\mathrm{ns}}$ & $0,47 b^{n s}$ & $0,45 \mathrm{~d}^{\mathrm{ns}}$ & $435 a^{\text {ns }}$ \\
\hline Ano 2 & Floresta & $4,68 \mathrm{a}$ & $0,28 \mathrm{~b}$ & $0,35 \mathrm{~d} B$ & $1,20 \mathrm{c}$ & 0,34 & $0,45 \mathrm{~d}$ & 449 a \\
\hline
\end{tabular}

* Letras minúsculas comparam os teores, de forma separada para cada área, ao longo dos tempos de coleta de amostras (a cada estação do ano, por dois anos); Letras maiúsculas comparam, dentro de cada estação do ano, a área de plantio com a área de 4,5 anos de idade da floresta; ns: os teores de $\mathrm{Mg}$, na área de floresta de 4,5 anos de idade, não apresentaram variação significativa entre os tempos de coleta.

Fonte: Elaborada pelos autores, 2020.

Conforme a Tabela 2, em relação ao o teor inicial de $\mathrm{N}$ nos resíduos levados a campo e coletados estacionalmente, houve uma diminuição no teor no primeiro período quente - verão (dez a março / ano 1) e mais acentuadamente no outono (março a junho / ano 2). Já no inverno e primavera do primeiro ano, os teores de nitrogênio no resíduo tenderam a aumentar, chegando, em dezembro deste ano, a um teor muito próximo ao inicial, para ambas as áreas de pesquisa. No segundo ano de estudo, um aumento gradativo no teor de nitrogênio foi verificado nas duas áreas.

Essas variações nos teores de $\mathrm{N}$ refletem um consumo inicial do nutriente por parte dos microrganismos decompositores, visando o seu estabelecimento, que, após ocorrido, tendem a acelerar o processo de decomposição visando ampliar a disponibilidade energética aos mesmos, a qual ocorre pela ampliação da decomposição e também por, possivelmente, junto ao resíduos coletado para análise, ocorrer a vinda de microrganismos que estavam em atuação na decomposição do resíduo dentro das bolsas de litter-bag. Considerando que a dinâmica do $\mathrm{N}$ entre as diferentes formas existentes no solo é rápida, a decomposição do resíduo em estudo pela ação 
do ambiente e dos microrganismos faz com que ocorra uma mineralização mais acentuada do nutriente, de acordo com o avanço da decomposição.

O P aumentou sua concentração com a permanência do resíduo na floresta, durante as três primeiras estações estudadas. Já na primavera seguinte houve uma diminuição no teor de P nas amostras (Tabela 2). Isto pode ter ocorrido devido ao tipo de solo da região, com elevado teor de argila, que pode ter incorporado este nutriente aos resíduos, através da fauna de solo e raízes, ocasionando uma elevação na concentração do mesmo. Ao final do primeiro ano de estudos, a concentração já foi menor em relação às avaliações anteriores, sendo que nas avaliações posteriores as concentrações de $\mathrm{P}$ se mantiveram relativamente estáveis.

O potássio, para ambas as áreas, apresentou comportamento nitidamente diferenciado entre o primeiro e o segundo ano de estudo, com seus teores decrescendo muito de um ano para o outro. Este elemento, por ser facilmente lixiviado pela água da chuva, pode ter sido perdido via lavagem, o que causou o grande decréscimo em seus teores, e esse decréscimo foi bem acentuado ao final do primeiro verão, pois as temperaturas elevadas e precipitações favoreceram a lavagem do $\mathrm{K}$ dos resíduos para o solo.

O Ca e o $\mathrm{Mg}$, por serem elementos estruturais das células vegetais (EPSTEIN e BLOOM, 2006), apresentaram variações relativamente pequenas na sua concentração durante o primeiro ano de estudo, para as duas áreas. No segundo ano, o Ca manteve o mesmo comportamento, porém o Mg, na área de plantio recente, atingiu teores mais elevados nos meses de março, junho e setembro, voltando a cair em dezembro. Este comportamento de relativa estabilidade nos teores entre as épocas de coleta e áreas de estudo está diretamente ligada ao comportamento fisiológico dos nutrientes, os quais são liberados majoritariamente junto à perda de massa do que da liberação exclusiva dos nutrientes da mesma para o solo.

O carbono orgânico apresentou elevação dos teores no segundo ano de estudo, para as duas áreas. Este fato ocorreu devido ao carbono, além de ser também um componente estrutural das células vegetais, ter, em função do processo de decomposição dos resíduos e mineralização dos nutrientes presentes no mesmo, uma dinâmica que envolve uma interface direta com a fauna de solo e raízes finas, as quais podem também, pela invasão das bolsas de litter-bags, trazer carbono (raízes finas, pequenas partículas de solo, microrganismos, etc.) e não somente permitir a sua liberação. Também deve-se destacar a qualidade do material em decomposição, que no caso de Pinus tendem a ser mais lignificados e de decomposição (liberação de carbono mais lenta) (BRUN et al., 2020).

A variação nos teores de enxofre apresentou nítida semelhança entre as duas áreas pesquisadas, ocorrendo uma diminuição no verão em relação ao teor inicial. A partir de então, houve um grande aumento no teor do elemento no outono, o qual se manteve elevado durante as duas estações seguintes (inverno e primavera). No verão seguinte, os teores de S apresentaram uma grande queda, muito semelhante ao que foi observado para o K, posicionando-se abaixo do teor inicial, os quais se mantiveram com poucas variações a partir de então, até o final da pesquisa. 
Em relação aos micronutrientes (Tabela 3), para o ferro foi observado um aumento da sua concentração nos resíduos após o período de campo, possivelmente causado pelo teor de Fe presente no solo. Considerando que o solo da área de estudo é de origem basáltica, o qual apresenta alto teores de óxidos de ferro complexados com a matéria orgânica, esta molécula pode ter "contaminado" o resíduo em decomposição, elevando os valores do elemento Fe, entre o primeiro e o segundo ano. Tal fato é também relatado por Viera et al. (2014), em estudos com o híbrido Eucalyptus urophylla $\times$ Eucalyptus globulus, onde também encontraram um aumento desse elemento na serapilheira foliar em processo de decomposição, associando o fato à contaminação da amostra com partículas de solo.

O boro teve suas concentrações levemente aumentadas nos resíduos coletados durante as quatro estações do primeiro ano de estudo. De acordo com Brighenti et al. (2013) e Ferri (1985), o boro é um elemento essencial para a formação da parede celular e é muito útil para a divisão e aumento no tamanho das células, portanto um elemento de características estruturais, o que em parte pode explicar a sua mais difícil dissociação, sendo um comportamento semelhante ao relatado para $\mathrm{Ca}$ e $\mathrm{Mg}$ no resíduo.

Tabela 3 - Teores de micronutrientes no resíduo depositado sobre o solo e recolhido após 3, 6, 9, 12, 15, 18, 21 e 24 meses de campo, no plantio e na floresta de 4,5 anos de Pinus taeda.

\begin{tabular}{|c|c|c|c|c|c|c|}
\hline \multirow{2}{*}{$\begin{array}{c}\text { Data de } \\
\text { Coleta }\end{array}$} & \multirow{2}{*}{ Local } & $\mathrm{Fe}$ & B & Zn & $\mathbf{C u}$ & Mn \\
\hline & & \multicolumn{5}{|c|}{$\mathrm{mg} \mathrm{kg}^{-1}$} \\
\hline \multirow{2}{*}{ Teor Inicial } & Plantio & $2692,0 \mathrm{~b}^{\mathrm{ns}}$ & $16,9 \mathrm{c}^{\mathrm{ns}}$ & $23,9 b^{\text {ns }}$ & $7,3 b^{\text {ns }}$ & $159,0 \mathrm{~ns}^{\mathrm{ns}}$ \\
\hline & Floresta & $2570,2 \mathrm{c}$ & $16,1^{\mathrm{ns}}$ & $25,7 \mathrm{c}$ & $7,9^{\text {ns }}$ & $145,0^{\mathrm{ns}}$ \\
\hline Verão / & Plantio & $3650,0 \mathrm{~b}^{\mathrm{ns}}$ & $23,1 \mathrm{a}^{\mathrm{ns}}$ & $45,3 \mathrm{ab}^{\mathrm{ns}}$ & $11,9 a^{\mathrm{ns}}$ & $154,5^{\text {ns }}$ \\
\hline Ano 1 & Floresta & $4080,0 \mathrm{~b}$ & 20,8 & $42,8 \mathrm{~b}$ & 11,9 & 154,5 \\
\hline Outono / & Plantio & $4082,0 \mathrm{~b}^{\mathrm{ns}}$ & $20,7 b^{\mathrm{ns}}$ & $44,1 \mathrm{ab}^{\mathrm{ns}}$ & $9,4 b^{\text {ns }}$ & 169,1 ns \\
\hline Ano 1 & Floresta & $3846,0 \mathrm{~b}$ & 17,2 & $49,5 \mathrm{a}$ & 11,6 & 152,1 \\
\hline Inverno / & Plantio & $3598,0 b^{\mathrm{ns}}$ & $19,2 b^{\mathrm{ns}}$ & $54,2 \mathrm{ab}^{\mathrm{ns}}$ & $8,8 b^{\text {ns }}$ & $174,7^{\text {ns }}$ \\
\hline Ano 1 & Floresta & $3842,0 \mathrm{~b}$ & 20,0 & $60,0 \mathrm{a}$ & 9,3 & 166,0 \\
\hline Primavera / & Plantio & $4199,0 \mathrm{~b} \mathrm{~A}$ & $19,6 b^{\mathrm{ns}}$ & 60,8 a $A$ & $10,7 b^{\mathrm{ns}}$ & $168,5^{\text {ns }}$ \\
\hline Ano 1 & Floresta & 3703,0 b B & 21,1 & 51,4 a B & 13,9 & 145,2 \\
\hline Verão / & Plantio & 6719,0 a $\mathrm{A}$ & 19,4 b B & $51,6 \mathrm{ab} A$ & 15,6 a $A$ & $205,1 \mathrm{~A}$ \\
\hline Ano 2 & Floresta & 3776,3 b B & $26,9 \mathrm{~A}$ & 43,5 b B & $11,0 \mathrm{~B}$ & $132,1 \mathrm{~B}$ \\
\hline Outono / & Plantio & 5839,0 a A & $15,7 \mathrm{c}^{\mathrm{ns}}$ & $49,1 \mathrm{ab} A$ & $15,1 \mathrm{a}^{\mathrm{ns}}$ & $188,9 \mathrm{~A}$ \\
\hline Ano 2 & Floresta & 4569,5 a & 18,1 & $39,5 b$ B & 12,1 & 114,6 B \\
\hline Inverno / & Plantio & 5472,5 a A & $16,3 \mathrm{c}^{\mathrm{ns}}$ & $44,6 \mathrm{ab}^{\mathrm{ns}}$ & $13,7 a^{\mathrm{ns}}$ & $197,3 \mathrm{~A}$ \\
\hline Ano 2 & Floresta & 4869,5 a B & 16,5 & $49,9 \mathrm{a}$ & 12,4 & $121,5 \mathrm{~B}$ \\
\hline Primavera / & Plantio & $4776,5 b^{n s}$ & $14,8 c^{n s}$ & $44,5 \mathrm{ab}^{\mathrm{ns}}$ & $14,3 a^{n s}$ & $152,9^{\mathrm{ns}}$ \\
\hline Ano 2 & Floresta & $4952,0 \mathrm{a}$ & 17,5 & $50,9 \mathrm{a}$ & 11,9 & 144,5 \\
\hline
\end{tabular}

* Letras minúsculas comparam os teores, de forma separada para cada área, ao longo dos tempos de coleta de amostras (a cada estação do ano, por dois anos); Letras maiúsculas comparam, dentro de cada estação do ano, a área de plantio com a área de 4,5 anos de idade da floresta, através do teste de Skott-Knott a 5\% de probabilidade de erro; ns: não ocorrência de variação significativa, conforme o tipo de comparação.

Fonte: Elaborada pelos autores, 2020.

O zinco apresentou aumentos gradativos em seus teores, para o resíduo coletado na floresta e no plantio, durante o primeiro ano de estudo. Na floresta, na avaliação da primavera do ano 1, ocorreu 
um pequeno decréscimo no teor do elemento. Solos rochosos tendem a apresentar elevados teores de Zn, assim como de Fe (MELLO e ALLEONI, 2019), fato que pode ter ocasionado uma troca mútua entre litter-bag e solo quanto ao Fe e Zn presente, mantendo-se um relativo equilíbrio do teor deste nutriente no complexo resíduo-solo.

Semelhante ao Zn, o cobre também aumentou sua concentração no material exposto no campo, na primeira avaliação, em relação ao teor inicial. Nas duas áreas, os teores foram variáveis a partir de então, com diminuições ocorrendo no outono e inverno do ano 1, voltando a aumentar na primavera do ano 1. Apesar dessas variações, mesmo sendo esse elemento considerado um metal pesado, os teores no resíduo não são considerados elevados (limite de até $40 \mathrm{mg} \mathrm{kg}^{-1}$ - SEIDEL et al., 2009), mas sendo assim possível entender o seu comportamento de pouca variação no resíduo em estudo, sendo, assim como $\mathrm{Ca}, \mathrm{Mg}$, Fe e $\mathrm{Zn}$.

Nos teores de manganês, as mudanças ocorridas podem ser consideradas pouco significativas, havendo um equilíbrio entre as diferentes avaliações, para as duas áreas de pesquisa, com a liberação do elemento sendo mais associada à liberação de massa seca do que em mudanças de teores no resíduo. Tal comportamento é similar aos demais micronutrientes estudados neste trabalho. Os teores de Mn no resíduo refletem os teores médios das plantas de origem e as importantes funções do elemento na planta, ligada diretamente à fotossíntese (TAIZ et al., 2017), tendo equilíbrio planta - resíduo - solo em função dos teores adequados em ambos, fazendo com que as plantas absorvam a quantidade necessária e acumulem a mesma em seus tecidos, posteriormente devolvendo ao solo pela ciclagem de nutrientes natural ou através da ação humana, como no presente estudo.

Para efeito silvicultural, pode-se estimar, com base na análise da amostra inicial e simulando-se a aplicação de uma quantidade média de $25 \mathrm{tha}^{-1}$ de resíduo, mesma quantidade usada no estudo com os litter bags, que teríamos um incremento de nutrientes na ordem de ( $\left.\mathrm{kg} \mathrm{ha}^{-1}\right): 85,0$ de N; 1,75 de P; 116,3 de K, 37,0 de Ca; 9,0 de Mg; 16,0 de S; 9650,0 de C; 67,3 de Fe; 0,42 de B; 0,60 de Zn; 0,18 de $\mathrm{Cu}$ e 3,98 de $\mathrm{Mn}$.

Viera et al. (2013) relatam que dentre os macronutrientes presentes no híbrido Eucalyptus urophylla $\times$ Eucalyptus globulus, , o potássio foi o que apresentou o maior coeficiente de devolução ao solo e o menor tempo médio de residência na serapilheira. O mesmo comportamento foi observado nesse estudo para o Pinus taeda, tanto para área de corte raso, quanto para a área coberta, quando comparado ao teor inicial (no primeiro ano) de nutrientes e o teor após os 2 anos.

Dentro de uma lógica de longo prazo, como sempre devem ser pensadas as práticas silviculturais sustentáveis, torna-se interessante a ideia de que a decomposição dos resíduos a serem distribuídos sobre o solo seja de velocidade baixa, uma vez que isso pode significar um maior aproveitamento por parte das plantas, dos nutrientes liberados. 


\section{CONCLUSÕES}

A liberação de resíduos para o solo, ao final de dois anos de avaliação, é maior na área de plantio em relação à área de floresta já estabelecida. A relativamente lenta decomposição destes resíduos serve como uma fonte de nutrientes de lenta liberação, os quais podem ser melhor aproveitados pelas plantas e, também, como um fator de proteção física do solo.

Ocorre uma relação linear entre a perda de resíduos para o solo em função do tempo de exposição das amostras, para ambas as áreas estudadas.

A variação nos teores de nutrientes nos resíduos coletados estacionalmente nas áreas de estudo mostra variações específicas, as quais ocorrem em função das características de cada elemento e das condições ambientais do local estudado. Há casos desde a manutenção dos teores em maior tempo, como $\mathrm{Ca}, \mathrm{Mg}$ e $\mathrm{K}$ (menor devolução de nutrientes no tempo) e perda rápida de teor no resíduo, como com o K.

A taxa de liberação de resíduos, nas condições estudadas, significa um grande incremento de nutrientes no solo, caso seja usada a prática de aplicação de resíduos antes da realização de um novo plantio, com a decomposição do material.

\section{REFERÊNCIAS}

ALVARES, A.C. et al. Climate classification map for Brazil. Meteorologische Zeitschrift, v. 22, n. 6, p. $711-728.2013$.

BAUER, D. et al. Acúmulo de serapilheira em fragmentos da Floresta Atlântica Subtropical. Revista Pesquisas, Série Botânica, v. 1, n. 71, p. 119-130, 2018.

BRIGHENTI, A.M. et al. Controle da braquiária associado à nutrição por Boro no cultivo do eucalipto em Sistema Silvipastoril. Circular Técnica n. 106. Juiz de Fora: Embrapa Gado de Leite, 2013. 7 p.

BRUN, E. J.; BRUN, F. G. K.; MEYER, E. A.; TRUBY, P. ; SCHUMACHER, M. V. Qualidade do solo em plantações de pinus no Sul do Brasil. Curitiba: Appris. 2020. 151 p.

BRUN, E.J.; SCHUMACHER, M.V. ; BRUN, F.G.K. Retorno de carbono e nitrogênio ao solo via distribuição de resíduos de madeira processada. Revista Ambiência, v. 6, n. 1, p. 47-60, 2010.

CIDADE-BRASIL. Município de Cambará do Sul. Disponível em: https://bit.ly/3bOpqgP. Acesso em: 15 de dez. 2020. 
CLIMATE-DATA. Clima Cambará do Sul (Brasil). https://bit.ly/2XJ0VZP. Acesso em: 06 Jul. 2020.

CUNHA NETO, F.V. et al. Acúmulo e decomposição da serapilheira em quatro formações florestais. Ciência Florestal, v. 23, n. 3, p. 379-387, 2013.

DICK, G.; D’ÁVILA, M.; SCHUMACHER, M. V. Produção de serapilheira em fragmento de Floresta Estacional Subtropical na região norte do Rio Grande do Sul. Ecologia e Nutrição Florestal, v. 3, n. 1, p. 1-8, 2015.

EPSTEIN, E.; BLOOM, A. J. Nutrição mineral de plantas - princípios e perspectivas. Trad. Maria Edna Tenório Nunes. 2. Ed. Londrina: Planta. 2006. 399 p.

FERREIRA, A. K. C. Avaliação de métodos de análises químicas de nutrientes em tecido vegetal. 91 f. 2014. Dissertação (Mestrado em Manejo de água e solo) - Programa de Pós-graduação em Manejo de Água e Solo. Universidade Federal do Semi-árido (UFERSA). Mossoró-RN.

FERRI, M.G. Fisiologia vegetal. São Paulo: EPU, 1985. 365p.

FRUMHOLF, P. C. Conserving wildlife in tropical forests managed for timber. Bioscience Journal, v. 45, n. 7,1995 . p. $456-464$.

GIÁCOMO, R.G.; PEREIRA, M.G.; MACHADO, D.L. Aporte e decomposição de serapilheira em áreas de Cerradão e Mata Mesofítica na Estação Ecológica de Pirapitinga - MG. Ciência Florestal, v. 22 , n. 4 , p. 669-680, 2012.

HOLANDA, A. C.; FELICIANO, A. L. P. ; MARANGON, L. C.; FREIRE, F. J.; HOLANDA, E. M. Decomposição da serapilheira foliar e respiração edáfica em um remanescente de Caatinga na Paraíba. Revista Árvore, Viçosa - MG, v. 39, n. 2, 2015. p. 245-254.

LOPES, V. G. et al. Quantificação de raízes finas em um povoamento de Pinus Taeda L. e uma área de campo em Cambará do Sul, RS. Ciência Florestal, v. 20, n. 4, p. 569-578, 2010.

LUZ, M. J. da S.; FERREIRA, G. B.; BEZERRA, J. R. C. Adubação e Correção do Solo: procedimentos a serem adotados em função dos resultados da análise do solo. Campina Grande - PB : Embrapa Algodão, 2002. 32p. 
MELO, V. F.; ALLEONI, L. R. F. (Orgs.) Química e mineralogia do solo. Viçosa: SBCS. 2019. 1381 p.

NUNES, E.N. et al. Análise da taxa de decomposição da serrapilheira na Reserva Ecológica Mata do Pau-Ferro, Areia-PB. Revista Gaia Scientia, v. 6, n. 1, p. 1-6, 2012.

REISSMANN, C.B.; WISNIEWSKI, C. Aspectos nutricionais de plantios de Pinus. In: Gonçalves, J.L. de M.; Benedetti, V. (Org.). Fertilização e Nutrição Florestal. Piracicaba: IPEF, 2005, p. 135-166.

SANTANA, J. A. DA S.; SOUTO, J. S. Produção de serapilheira na Caatinga da região semi-árida do Rio Grande do Norte, Brasil. Revista IDESIA, v. 29, n. 2, p. 87-94, 2011.

SCHUMACHER, M.V. et al. Produção de biomassa no corte raso em plantio de Araucaria angustifolia (Bertol.) Kuntze em 27 anos de idade em Quedas do Iguaçu, PR. Ciência Florestal, v. 21, n. 1, p. 53-62, 2011.

SEIDEL, E. P. ; DA COSTA, A. C. S.; LANA, M. C. Fitodisponibilidade de cobre e produção de matéria seca por plantas de milho em resposta à aplicação de dejetos de suínos. Revista Brasileira de Ciência do Solo, v. 33, p. 1871-1878. 2009.

SIGNOR, D.; DIONISIO, J.A. Decomposição de resíduos orgânicos. In: DIONISIO, J. A.; PIMENTEL, I. C.; SIGNOR, D.; PAULA, A. M. de; MACEDA, A.; MATANNA, A. L. Guia prático de biologia do solo. Curitiba: SBCS: NEPAR, 2016. Disponível em: https://bit.ly/3qg8MdN. Acesso em: 28/12/2020.

STRECK, E.V. et al. Solos do Rio Grande do Sul. 3. ed., Porto Alegre, RS: UFRGS: EMATER/ RS-ASCAR, 2018. 251 p.

SUTILI, F.J.; SCHUMACHER, M.V. Perda de peso e conteúdo de nutrientes minerais do folhedo de uma floresta estacional decidual durante a decomposição. Santa Maria: Laboratório de Ecologia Florestal-CCR-UFSM. 2002. 16 p. (Relatório de Pesquisa).

TAIZ, T.; ZEIGER, E.; MØLLER, I. M.; MURPHY, A. Fisiologia e Desenvolvimento Vegetal. 6. ed. Porto Alegre: Artmed. 2017. 888 p.

TEDESCO, M.J. et al. Análise de solo, plantas e outros materiais. Porto Alegre: UFRGS. (Boletim Técnico). 1995. 118 p. 
VALENTINI, C.M.A. et al. Produção, acúmulo e decomposição de serapilheira em uma área revegetada do Parque Estadual Massairo Okamura em Mato Grosso. Revista Holos, v. 5, n. 30, p. 211-221, 2014.

VIERA, M.; SCHUMACHER, M.V. ; BONACINA, D.M. Biomassa e nutrientes removidos no primeiro desbaste de um povoamento de Pinus taeda L. em Cambará do Sul, RS. Revista Árvore, v. 35, n. 3, p. 371-379, 2011.

VIERA, M.; SCHUMACHER, M.V. ; CALDEIRA, M.V. W. Dinâmica de decomposição e nutrientes em plantio de Eucalyptus urophylla $\times$ Eucalyptus globulus no Sul do Brasil. Floresta e Ambiente, v. 20, n. 3, p. 351-360, 2013.

VIERA, M.; SCHUMACHER, M.V. ; ARAÚJO, E.F. Disponibilização de nutrientes via decomposição da serapilheira foliar em um plantio de Eucalyptus urophylla $\times$ Eucalyptus globulus. Floresta e Ambiente, v. 21, n. 3, p. 307-315, 2014. 
